\title{
Soil Collapse Monitoring with EM Measurements
}

\author{
Henok Hailemariam ${ }^{1}$, Ahmed Al-Janabi ${ }^{1}$, Frank Wuttke ${ }^{1}$, Norman Wagner ${ }^{2}$ \\ ${ }^{1}$ Marine and Land Geomechanics and Geotechnics, Kiel University \\ Ludewig-Meyn-Straße 10, 24118, Kiel, Germany \\ henok@gpi.uni-kiel.de; al-janabi@gpi.uni-kiel.de; fw@gpi.uni-kiel.de \\ ${ }^{2}$ Institute of Material Research and Testing (MFPA), Bauhaus-University Weimar \\ Coudraystraße 4, 99423, Weimar, Germany \\ norman.wagner@mfpa.de
}

\begin{abstract}
Collapsible soils, widely regarded as problematic soils, undergo large volume changes when subjected to saturation by water, which in turn causes damage on the structures unwittingly built on such deposits. In this work, a new approach for the monitoring of water caused deterioration process in collapsible soils based on experimental high frequency electromagnetic (HF-EM) investigations with an open ended coaxial line technique is presented. The tests are performed in a one dimensional controlled loading cell under simultaneous measurements of complex dielectric permittivity or conductivity, vertical stress, deformation and other soil hydro-mechanical conditions. A strong increase in the values of complex dielectric permittivity of the collapsible soil was observed at a critical water content, which triggered the collapse by means of chemical reactions of water with clay and/or silt bridges, which hold and bind the relatively coarser grained particles in the soil structure. These reactions produce, changes in the soil structure, and a rise in the concentration of $\mathrm{Na}^{+}, \mathrm{Ca}^{++}, \mathrm{OH}^{-}$and other alkali ions in the pore water solution, thus increasing the complex dielectric permittivity of the soil. Furthermore, the variations of the complex dielectric permittivity of the collapsible soil with water content, porosity, matric suction and vertical stress were studied independently and in different joint combinations, as the collapse mechanism is highly influenced by soil hydro-mechanical conditions. In this regard, the physical relationship between HF-EM soil properties in terms of the frequency dependent complex dielectric permittivity and soil hydro-mechanical conditions is theoretically analyzed with an advanced theoretical HF-EM mixture model.
\end{abstract}

Keywords: collapsible soil, complex dielectric permittivity, water content, porosity

\section{Introduction}

Collapsible soils are weak soils that appear to be stable in their natural state, normally dry condition, but rapidly deform under saturation (wetting), thus generating large and often unexpected settlements which often yield disastrous consequences for structures unwittingly built on such deposits. Naturally occurring collapsible soils usually exist at or near dry state as they are primarily found in arid and semi-arid regions of the world. The focus of this research is on dry uncemented collapsible soils which may be remolded or found in an undisturbed state in nature. The triggering mechanism for the water-driven collapse in dry collapsible soils is attributed mainly to the weakening or softening of a portion of the fine-grained fraction of soil, which exist as a bonding material for the larger-grained particles [1], and also due to the loss of strength due to a reduction in matric suction as a result of wetting [2]. The matric potential is a measure of the bonding forces between soil and water. The amount of total suction and the degree of saturation in soils are mainly used to describe the hydraulic water conditions (soil-water characteristic curve - SWCC). Moreover, the SWCC is an important tool in the study of the complex behavior of unsaturated soils [3].

The microscopic behavior of collapsible soils is governed by the presence of minerals such as tecosilicates, mica, and clay minerals of smectite, chlorite and kaolinite. The volume change and shear strength in terms of the macroscopic behavior of the individual clay platelets are mostly controlled by surface physicochemical forces, rather than gravitational forces [4]. This is attributed to their small size and the diffuse double layer formed around clay platelets. Comprehensive study of the electromagnetic properties of collapsible soils obtained from HF-EM measurement techniques can be used to explain microscopic mechanisms of collapse during saturation due to physiochemical forces. 
HF-EM measurement techniques such as capacitance methods [5], ground penetrating radar (GPR) [6] or time domain reflectometry (TDR) [7] work on the basis of detecting changes in spatial and temporal variations of the HF-EM properties at or near the subsurface [8]. At lower frequency ranges from $1 \mathrm{MHz}$ to $200 \mathrm{MHz}$ capacitance methods are commonly used to determine complex permittivity. In the frequency range from $1 \mathrm{MHz}$ to $10 \mathrm{GHz}$ time or frequency domain reflectometry techniques are usually employed [9].

This paper documents the results of a laboratory experimental study to monitor water-driven deterioration process of stressed collapsible soils using electromagnetic waves. One dimensional controlled loading tests, where water is introduced at different stages of loading to simulate collapse of soil, are carried out with simultaneous measurements of complex dielectric permittivity or conductivity, vertical stress and deformation. This is achieved by integrating an open ended coaxial line with a one dimensional controlled loading setup apparatus. The influence of changes in water content, porosity and matric suction on the electromagnetic properties of collapsible soils is investigated theoretically and experimentally, as these factors play a vital role in the collapse mechanism of collapsible soils.

\section{Electromagnetic Properties of Soil}

\subsection{Background}

The response of a material to a traveling electromagnetic wave is characterized as dielectric permittivity. Soil can be viewed as a dielectric with electromagnetic properties of magnetic permeability, permittivity and effective conductivity [4]. Since most naturally occurring soils are non-ferromagnetic, the permittivity and effective conductivity are able to fully describe the dielectric responses of soil in an electromagnetic field. These two properties have been used to predict soil moisture, porosity and presence of contaminants $[10,11]$. Permittivity is a complex

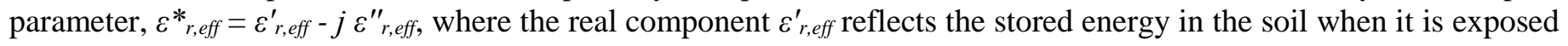
to time harmonic electromagnetic field with angular frequency $\omega=2 \pi f$ [8]. While the imaginary part, $\varepsilon^{\prime \prime}{ }_{r, e f f}=$ $\varepsilon^{\prime \prime}{ }_{d}+\sigma_{D C}\left(\omega \varepsilon_{0}\right)$, characterizes the Ohmic and polarization losses [12]. Here $\varepsilon^{\prime \prime}{ }_{d}$ and $\sigma_{D C} /\left(\omega \varepsilon_{0}\right)$ are the dielectric and conductive losses respectively and $\varepsilon_{0}$ is the permittivity of free space [7,13]. Generally, the polarization of the material (in terms of complex effective permittivity) increases monotonically from microwaves to very low frequencies.

\subsection{Broadband Dielectric Mixture Model}

The broadband theoretical frequency and temperature-dependent mixing rule suggested by Wagner et al. [9], which is called advanced Lichtenecker and Rother Model (ALRM), Equations 1, is used to analyse the complex dielectric permittivity of the collapsible soil.

$$
\varepsilon_{r, e f f}^{* a(\theta, n)}=\theta \varepsilon_{w}^{* a(\theta, n)}(\omega, T)+(1-n) \varepsilon_{G}^{a(\theta, n)}(\omega, T)+(n-\theta)
$$

where $n$ is the soil porosity, $\theta$ is the volumetric water content $\left(\mathrm{m}^{3} \mathrm{~m}^{-3}\right), \varepsilon^{*}{ }_{w}$ is the complex permittivity of pore water, structural exponent $0 \leq a \leq 1$ and $\varepsilon_{G}$ is the relative real permittivity of the solid grain particles. A structural exponent $a=1 / 2$ (exponent selected according to CRIM, [14]) is used to analyse the complex dielectric permittivity of the studied collapsible soil, due to its comprehensive use of all soil phase forms and accuracy of prediction [7, 9, 15]. For $a=1 / 3$, Equation 1 transforms to the Looyenga-Landau-Lifschitz model (LLLM) [16, 17].

$$
\begin{gathered}
\varepsilon_{G}=\left(1.01+0.44 G_{S}\right)^{2}-0.062 \\
\varepsilon_{a}=3.03+9.3 \theta+146.0 \theta^{2}-76.7 \theta^{3}
\end{gathered}
$$

The pore fluid is an aqueous solution, and the temperature, frequency and porosity-dependent relative effective complex dielectric permittivity is obtained according to the modified Debye model $[18,19]$. The equation suggested by Dobson et al. [20], Equation 2, is used to obtain the relative real permittivity of the solid grain particles of the

studied collapsible soil. The term $G_{s}$ in Equation 2 represents the specific gravity of solid particles. The prediction of the ALRM and experimental findings in this research are further compared to the Topp et al. [13] model. According to 
Topp et al., the real apparent relative permittivity $\varepsilon_{a}$ of soil can be obtained based on the volumetric water content $\theta\left(\mathrm{m}^{3} \mathrm{~m}^{-}\right.$ ${ }^{3}$ ) of the soil as shown in Equation 3.

\section{Experimental Program}

\subsection{Tested Soil}

Remolded collapsible soil taken from near Baku area, Azerbaijan, at a depth range of $2.0 \mathrm{~m}$ to $2.5 \mathrm{~m}$ was used for the experimental investigation. The common geotechnical and physiochemical properties of the collapsible soil (obtained following ASTM D420-D5876 [21]) are listed in Table 1. Phase content was determined quantitatively by combined X-ray diffraction (XRD) and X-ray fluorescence (XRF) analysis.

Table 1: Geotechnical and physiochemical properties of the studied collapsible soil.

\begin{tabular}{|c|c|c|c|}
\hline Property & Value & Property & Value \\
\hline Specific gravity $\left(\mathrm{g} \mathrm{cm}^{-3}\right)$ & 2.735 & Classification $(U S C S)^{*}$ & CL \\
\hline Initial water content $w(\%)$ & 9.3 & Organic content (\%) & 5.811 \\
\hline Liquid limit $(\%)$ & 31.3 & Lime content (\%) & 12.944 \\
\hline Plastic limit (\%) & 17.0 & Tecosilicates (\%) & 44 \\
\hline Plastic index (\%) & 14.3 & Mica (\%) & 25 \\
\hline Clay \% (<0.002 mm) & 34 & Smectite (\%) & 7 \\
\hline Silt \% (0.002-0.063 mm) & 51 & Chlorite (\%) & 5 \\
\hline Sand \% $(0.063-2 \mathrm{~mm})$ & 15 & Kaolinite (\%) & 3 \\
\hline
\end{tabular}

* USCS unified soil classification system

\subsection{Experimental Procedure and Test Setup}

This section describes the experimental methodology and devices used to analyse the interrelationship between hydromechanical properties, collapse mechanism and dielectric behavior of collapsible soils.

The effect of changes in water content and porosity of collapsible soil on the complex dielectric permittivity was analysed experimentally by conducting complex dielectric permittivity measurements on the collapsible soil, with initial void ratios of $e_{0}=0.83$ (natural loose condition) and $e_{0}=0.43$ (lab compacted condition), for the full range of soil saturation. The soil specimens were incrementally wetted from air dry up to saturation with distilled water and were then allowed to equilibrate for 48 hours. The soil bulk density, porosity, gravimetric water content and matric suction were controlled, and the measurements were repeated at least three times for each specimen. Furthermore, the results were used to analyse the variations of matric suction with complex dielectric permittivity of collapsible soils based on experimental findings. The matric suction measurements of the collapsible soil used for electromagnetic tests, were performed using the filter paper method as per ASTM D 5298 [22] guidelines. Care was taken when measuring matric suction, because intimate contact between the filter paper and the soil is very important for the determination of matric suction by the filter paper method. The filter paper water content measurements were performed by two persons in order to decrease the time during which the filter papers are exposed to the laboratory atmosphere and, thus, the amount of moisture lost and gained during measurements was kept to a minimum. The moisture content measurements were weighed to nearest $0.1 \mathrm{mg}$. accuracy, and the matric suction was determined according to the appropriate filter paper calibration curves as given by ASTM D 5298 [22].

One dimensional loading tests on the collapsible soil at natural loose condition $e_{0}=0.83$ were performed in a cylindrical test box having an inside dia. of $154 \mathrm{~mm}$ and with a specimen height of $60 \mathrm{~mm}$, with a pressure controlled loading machine, Figure 1. Electromagnetic measurements were taken simultaneously with the help of an open ended coaxial line connected to a Sequid portable Stability Time Domain Reflectometer STDR-65 and fitted horizontally to the test box to monitor the changes in complex dielectric permittivity, due to loading and during water-driven collapse of the collapsible soil. The test box consists of an outer steel frame with an inner lining of plexi-glass. The outer frame avoids lateral bending that may occur due to loading. The deformation behavior of collapsible soil depends considerably on the stiffness of the walls of the test box. The use of plexi-glass as an inner lining helps to limit the amount of shear stress between the glass wall and the soil mass and ensures that actual plane-strain conditions are met. A digital linear transducer 
was used to record the deformation of specimen, which was stored in a data logger attached to the system. Two types of one dimensional loading tests were performed. The first test was done on a collapsible soil at optimum moisture condition (for maximum dry density from standard Proctor test), $w=0.18 \mathrm{~g} \mathrm{~g}^{-1}$, to analyse the effect of changes in the vertical stress on the complex dielectric permittivity of the collapsible soil. The specimen was loaded with predefined loading steps up to a maximum of $400 \mathrm{kPa}$, and then followed with unloading back to initial condition. The electromagnetic measurements were done before and after each load step to observe the changes in the complex dielectric permittivity of the collapsible soil due to the load increments. The second, water-driven collapse test, was performed on the collapsible soil which was initially at natural condition $\left(w=0.093 \mathrm{~g} \mathrm{~g}^{-1}\right)$. Afterwards, the specimen was loaded by a stress of $50 \mathrm{kPa}$ (equivalent to the in-situ soil overburden pressure) and then inundated with distilled water from an overhead water reservoir [23] until saturation to monitor the progress of collapse of the specimen with time. Complex dielectric permittivity measurements were taken at regular intervals throughout the test, to monitor changes in the complex dielectric permittivity of the soil with the progression of specimen collapse.
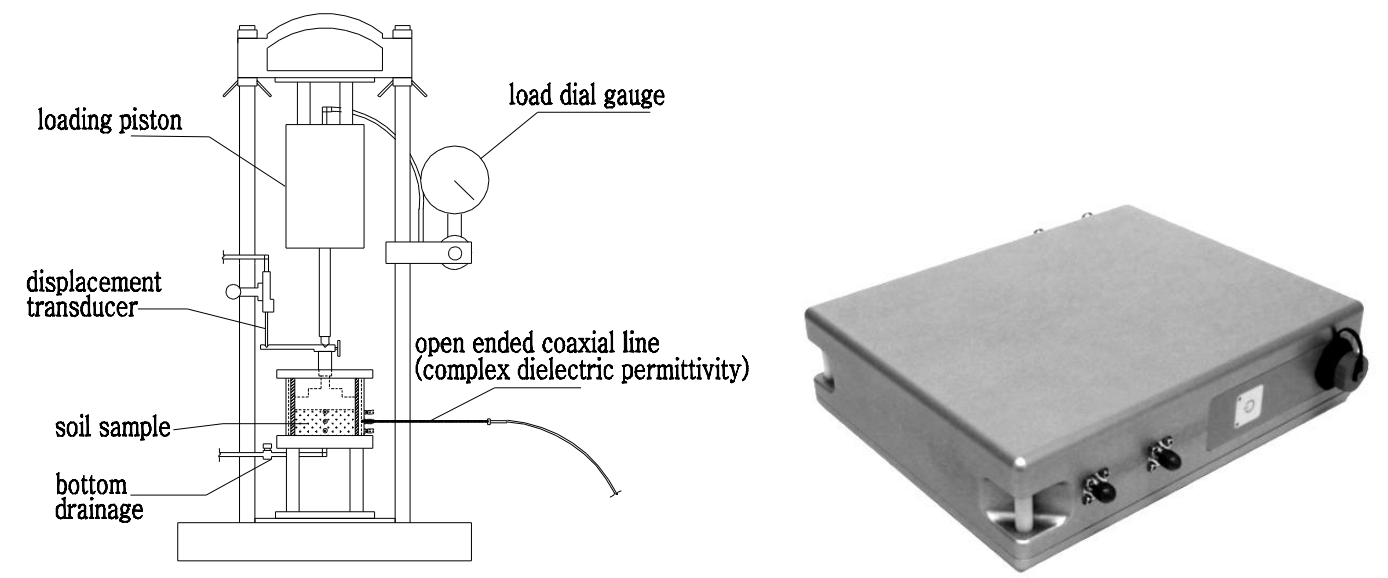

Fig. 1: Experimental setup of one dimensional controlled loading test (left) and portable Sequid STDR-65 (right).

\subsection{Determination of Soil Complex Dielectric Spectra}

The broadband dielectric measurements were performed in the stable frequency range from $100 \mathrm{MHz}$ to $1 \mathrm{GHz}$ at room temperature and atmospheric pressure by means of TDR technique with an open ended coaxial line [9]. A probe with dia. of $2.2 \mathrm{~mm}$ and length of $175 \mathrm{~mm}$ connected via a coaxial cable to a Sequid STDR-65 device was used for the measurements. The resolution of the STDR-65 is $10 \mathrm{ps}$ and the sampling interval is $50 \mathrm{~ns}$. The acquired step-like TDR time-domain curves are pre-processed in the TDR and subsequently transmitted to a laptop computer, which transforms the signals into the frequency domain using the Fast-Fourier Transform (FFT) and carries out the calibration and permittivity calculations [24]. Prior to the measurements a two step calibration procedure was performed to minimize errors in measurement resulting from device and setup. Initially, full one port three-term calibration was done mechanically with (Open, Short, $50 \Omega$-Match or Load) calibration standards following procedure by Rhode \& Schwarz N $-50 \Omega \mathrm{ZV}-\mathrm{Z} 21$. The second stage (permittivity calibration) was then performed by measuring the complex scattering parameter $S_{11}$ of three materials: air, distilled water and a short circuit. Each calibration standard was measured using 10 averages. The calculation of the relative effective complex dielectric permittivity $\varepsilon_{r, \text { eff }}$ was obtained as shown in Equation 4 [25]. The terms $c_{i}$ in Equation 4 are three temperature and frequency dependent complex calibration parameters obtained from the permittivity calibration and $S_{11}$ is the measured complex reflection coefficient of the soil.

$$
\varepsilon_{r, e f f}^{*}(\omega, T)=\frac{c_{1}(\omega, T) S_{11}(\omega, T)-c_{2}(\omega, T)}{c_{3}(\omega, T)-S_{11}(\omega, T)}
$$

\section{Results and Discussion}




\subsection{Variation of $\varepsilon^{*}$,eff with Water Content and Porosity of Collapsible Soil}

The results of electromagnetic measurements on collapsible soil samples at natural loose condition $\left(e_{0}=0.83\right)$ and lab compacted condition $\left(e_{0}=0.43\right)$ are shown in Figure 2. In Figure 2 (top), variations of the real $\varepsilon_{r, e f f}^{\prime}$ and imaginary $\varepsilon_{r, \text { eff }}^{\prime \prime}$ parts of relative effective complex dielectric permittivity of collapsible soil at a measurement frequency of $1 \mathrm{GHz}$ with gravimetric water content $w$ are presented. The values of the relative effective complex dielectric permittivity at a particular frequency range of around $1 \mathrm{GHz}$ are selected from the spectra in order to compare the dispersion and absorption directly $[25,26,27]$. The results are compared to the ALRM presented in this study and the frequently used empirical relationship suggested by Topp et al. [13]. Topp et al. determined the effective dielectric permittivity from TDR measurements using $30 \mathrm{~cm}$ and $1 \mathrm{~m}$ long coaxial probes. Hence, a dependence of the effective measurement frequency on moisture content is to be expected. With increasing moisture content, the effective measurement frequency which corresponds to the apparent real relative permittivity of the TDR signal decreases due to low pass behavior in soils with considerable clay fraction $[28,29]$. This consequently affects the apparent permittivity of the soil.
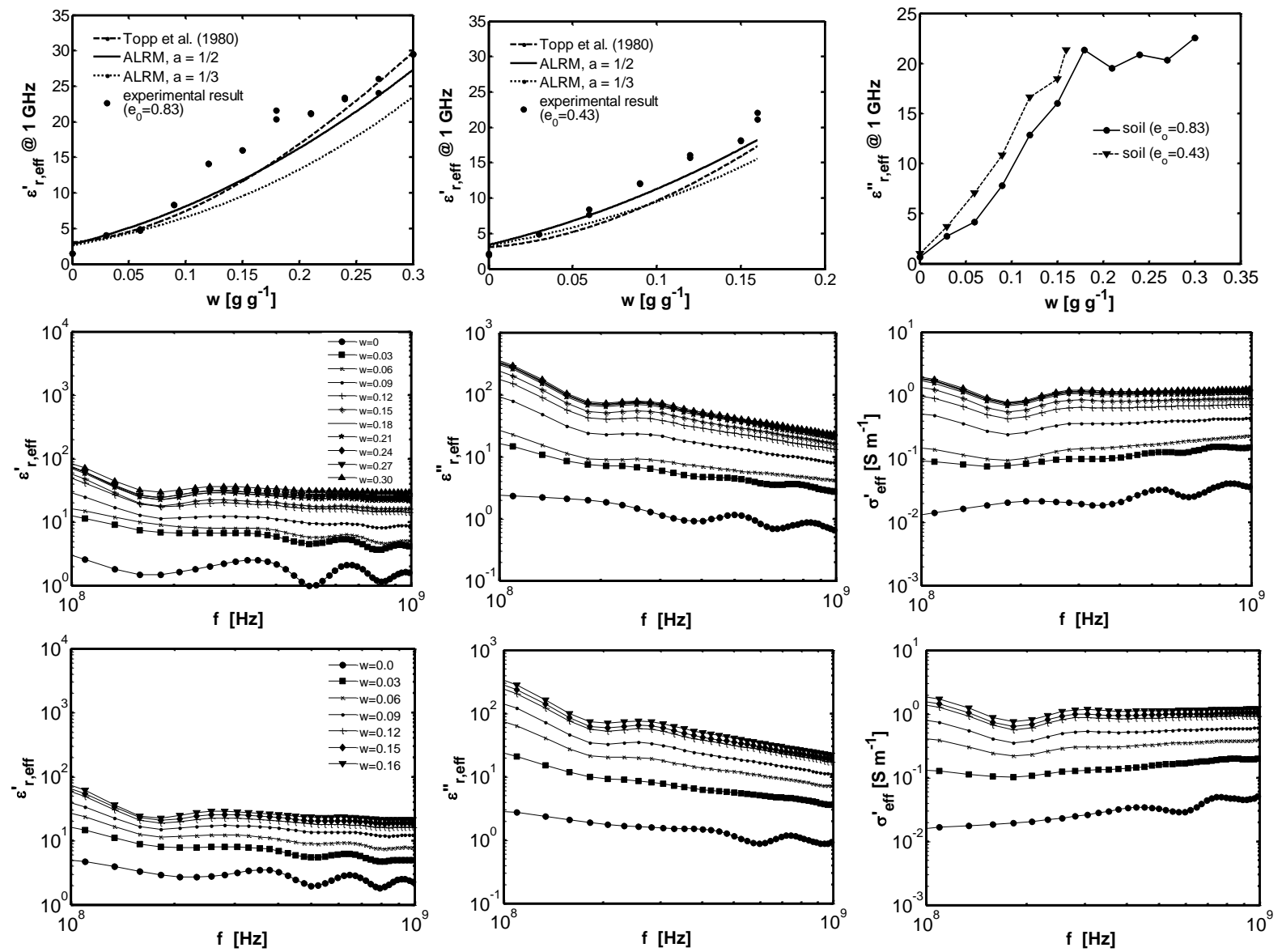

Fig. 2: Variation of $\varepsilon_{r, \text { eff }}^{\prime}$ and $\varepsilon^{\prime \prime}{ }_{r, \text { eff }}$ with gravimetric water content $w$ (top), $\varepsilon_{r, \text { eff }}$ and $\sigma_{\text {eff }}^{\prime}=\omega \varepsilon_{0} \varepsilon_{r, \text { eff }}^{\prime \prime}$ as functions of frequency $f$ for collapsible soil at loose natural condition $e_{0}=0.83$ (middle) and at lab compacted condition $e_{0}=0.43$ (bottom).

The measured $\varepsilon_{r, \text { eff }}^{\prime}$ of the collapsible soil at loose saturated condition $\left(e_{0}=0.83\right), \varepsilon_{r, \text { eff }}^{\prime} @ 1 \mathrm{GHz}=29.42$, is much higher than that of the collapsible soil at lab compacted saturated condition $\left(e_{0}=0.43\right), \varepsilon_{r, \text { eff }}^{\prime} @ 1 \mathrm{GHz}=21.12$, Figure 2 (top). This is mainly due to the fact that the collapsible soil at loose saturated condition (comparatively with a higher void ratio), has a relatively higher amount of liquid phase (pore fluid) at saturated condition, which results in a much better conducting pathway for dielectric permittivity or conductivity, and hence a higher $\varepsilon_{r, \text { eff }}^{\prime}$ is obtained [30,31]. However, the difference between the measured $\varepsilon_{r, \text { eff }}$ of the collapsible soil at loose saturated condition $\left(e_{0}=0.83\right), \varepsilon_{r, e f f}^{\prime \prime} 1 \mathrm{GHz}=22.57$, and the collapsible soil at lab compacted saturated condition $\left(e_{0}=0.43\right), \varepsilon^{\prime \prime}{ }_{r, \text { eff }} @ 1 \mathrm{GHz}=21.34$, is relatively insignificant. The $\varepsilon^{\prime \prime}$ reff 
of the soil is mainly influenced by the amount of dissolved solutes in the pore water solution and the corresponding Ohmic and polarization losses $[12,31]$ when the soil is subjected to an electromagnetic wave, which are both not significantly affected by changes in soil porosity. All three models i.e. the ALRM with $a=1 / 2 \& a=1 / 3$ and the Topp et al. model, underestimate the measured $\varepsilon_{r, \text { eff }}^{\prime}$ for a wide range of soil saturation, Figure 2 (top). However, the ALRM with $a=1 / 2$ and the Topp et al. model provide a better match with experimental data for gravimetric water content $w$ between $0-0.10 \mathrm{~g} \mathrm{~g}^{-1}$ and $0.23-0.30 \mathrm{~g} \mathrm{~g}^{-1}$ for collapsible soil with $e_{0}=0.83$, and between $0-0.07 \mathrm{~g} \mathrm{~g}^{-1}$ for collapsible soil with $e_{0}=0.43$, as compared to the ALRM with $a=1 / 3$.

In Figure 2 (middle and bottom), the frequency dependence of the relative effective complex dielectric permittivity $\varepsilon_{r, \text { eff }}$ of the investigated collapsible soil at different levels of soil saturation is presented. As is the case in clay minerals, collapsible soils show variations in the complex dielectric permittivity and effective conductivity with changes in frequency, the phenomenon of which is called dielectric dispersion or relaxation. This is attributed primarily to certain polarization mechanisms, and the corresponding curves are known as dielectric spectra [10]. The magnitude of dielectric dispersion in the frequency range $0.1 \mathrm{MHz}-1 \mathrm{GHz}$ is defined as the difference in magnitude at high and low frequencies at which the relative effective complex dielectric permittivity curve levels off. This value has been shown to be highly influenced by the mineralogical and mineral solution interface characteristics of the soil [10]. In principle, the open-ended coaxial probe and the calibration procedure used to perform the measurements enable an accurate determination of the frequency dependence of the effective complex dielectric permittivity.

\subsection{Variation of $\varepsilon^{*}$ reff with Matric Suction of Collapsible Soil}

Very few experimental investigations are present regarding the influence of soil suction on the electromagnetic material properties of unsaturated soils $[26,27]$. In this research, experimental results of simultaneous measurements of complex dielectric permittivity and matric suction of collapsible soil are presented. In Figure 3, results depicting the variations between gravimetric water content $w$, matric suction $\psi_{m}$ and complex dielectric permittivity $\varepsilon_{r, \text { eff }}$ are shown. For both initial void ratios $\left(e_{0}=0.83\right.$ and $\left.e_{0}=0.43\right)$, the recorded values of the $\varepsilon_{r, \text { eff }}^{\prime}$ are similar at the start of the wetting procedure (dry condition). As the matric suction $\psi_{m}$ of the soils is lowered beyond the water entry value (WEV) and then further towards full saturation by increasing the gravimetric water content $w$, the measured $\varepsilon_{r, \text { eff }}^{\prime}$ at natural loose condition increases rapidly as compared to that of the collapsible soil at lab compacted condition, due to its higher void ratio and hence higher amount of entrapped pore water resulting in better conducting pathways for dielectric permittivity or conductivity, Figure 3 (middle). The noticeable increase seen in the measured $\varepsilon_{r, \text { eff }}^{\prime}$ of the loose collapsible soil at or near saturated state, is rather absent in the values recorded for the $\varepsilon^{\prime \prime}{ }_{r, e f f}$, as the $\varepsilon^{\prime \prime}{ }_{r, \text { eff }}$ is not significantly affected by changes in soil porosity, Figure 3 (right). Rather the $\varepsilon_{r \text {,eff }}^{\prime \prime}$ of soil represents the Ohmic and polarization losses associated with the amount of solutes dissolved in the pore water solution of the soil, which are both not significantly influenced by changes in soil porosity.
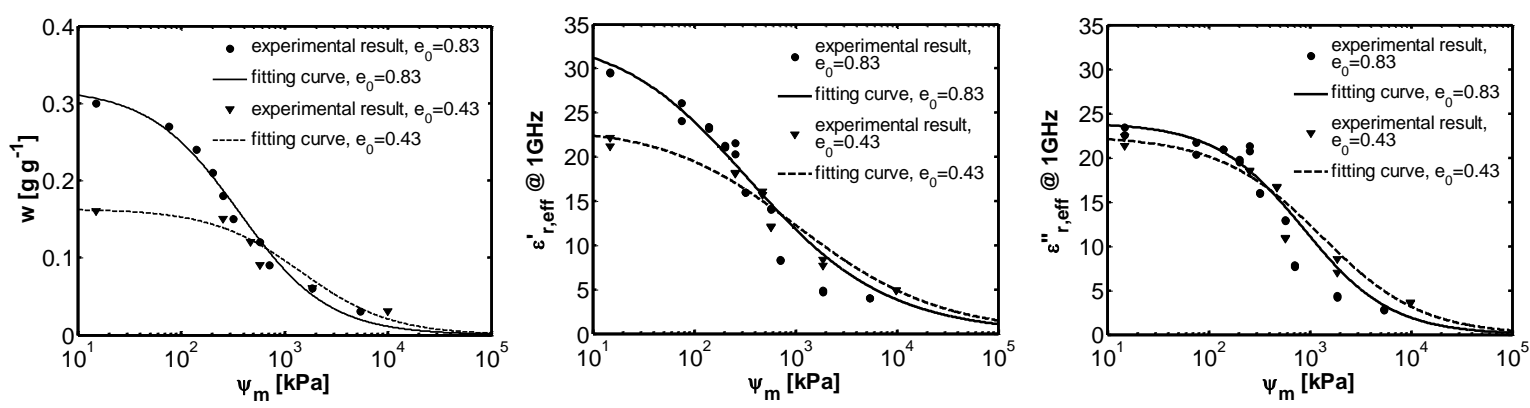

Fig. 3: SWCC (left), variation of $\varepsilon_{r, \text { eff }}^{\prime}\left(\right.$ middle) and $\varepsilon_{r, \text { eff }}^{\prime \prime}$ (right) with matric suction $\psi_{m}$ of collapsible soil with $e_{0}=0.83$ and $e_{0}=0.43$.

\subsection{Variation of $\varepsilon^{*}$,eff with Applied Vertical Stress of Collapsible Soil}

Figure 4 shows the results of electromagnetic measurements taken during a one dimensional controlled loading test on a collapsible soil at natural loose condition $e_{0}=0.83$ and with optimum moisture content for maximum dry density from standard Proctor test $\left(w=0.18 \mathrm{~g} \mathrm{~g} \mathrm{~g}^{-1}\right)$. The $\varepsilon_{r, \text { eff }}$ of the collapsible soil increases with load until the maximum applied stress of $400 \mathrm{kPa}$ is reached, Figure 4 (top). The rise in the measured $\varepsilon_{r, e f f}$ is particularly evident during the onset of stress change. The increase in the $\varepsilon *_{r, \text { eff }}$ of the collapsible soil is attributed to the changes in soil 
structure and rearrangement of the solid grains upon loading, with a resulting better grain to grain contact and increased volumetric water content of soil (removal of entrapped pore air during specimen deformation). This produces an increase in the contact points between solid grains and pore water (seen by the increase in the values of the measured $\varepsilon_{r, \text { eff }}^{\prime}$ ) as well as contact points between solid grains and dissolved solutes (seen by the increase in the values of the measured $\varepsilon^{\prime \prime}{ }_{r, e f f}$ ). Whereas, as expected, during the unloading stage, insignificant changes in the $\varepsilon^{*}$,eff of the collapsible soil are recorded, due to the low deformation recovery (elasticity) of collapsible soils upon unloading, which in turn produces negligible changes in the soil structure.
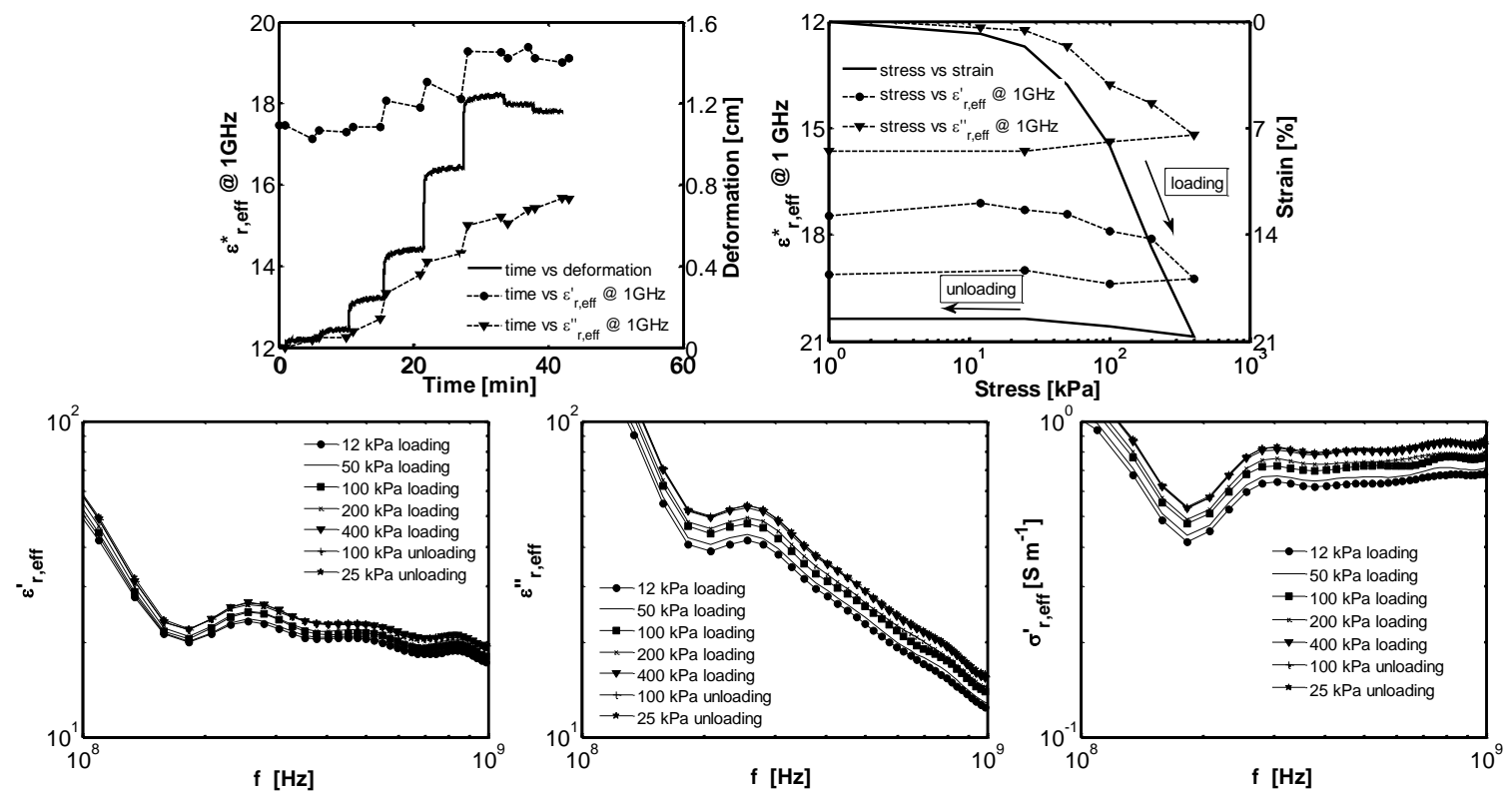

Fig. 4: Plot of time with $\varepsilon^{*}{ }_{r, \text { eff }}$ and deformation (top-left), vertical stress with $\varepsilon^{*}{ }_{r, e f f}$ and vertical strain of sample (top-right) and $\varepsilon^{*}{ }_{r, e f f} \&$ $\sigma_{e f f}^{\prime}=\omega \varepsilon_{0} \varepsilon_{r, e f f}^{\prime \prime}$ as functions of frequency $f$ (bottom) of a loading test on a soil at optimum moisture condition $\left(w=0.18 \mathrm{~g} \mathrm{~g}^{-1}\right)$.

\subsection{Variation of $\varepsilon^{*}$,eff During a Water-driven Deterioration Process of Collapsible Soil}

Figure 5 shows the results of one dimensional collapse test on a collapsible soil at natural loose condition $e_{0}=0.83$ and with initial gravimetric water content $w=0.093 \mathrm{~g} \mathrm{~g}^{-1}$ upon wetting at a stress level of $50 \mathrm{kPa}$.
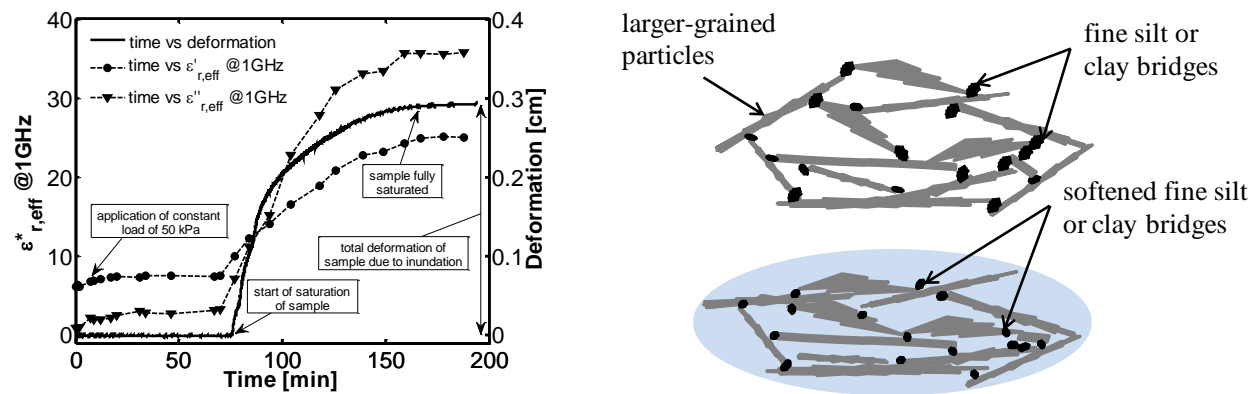

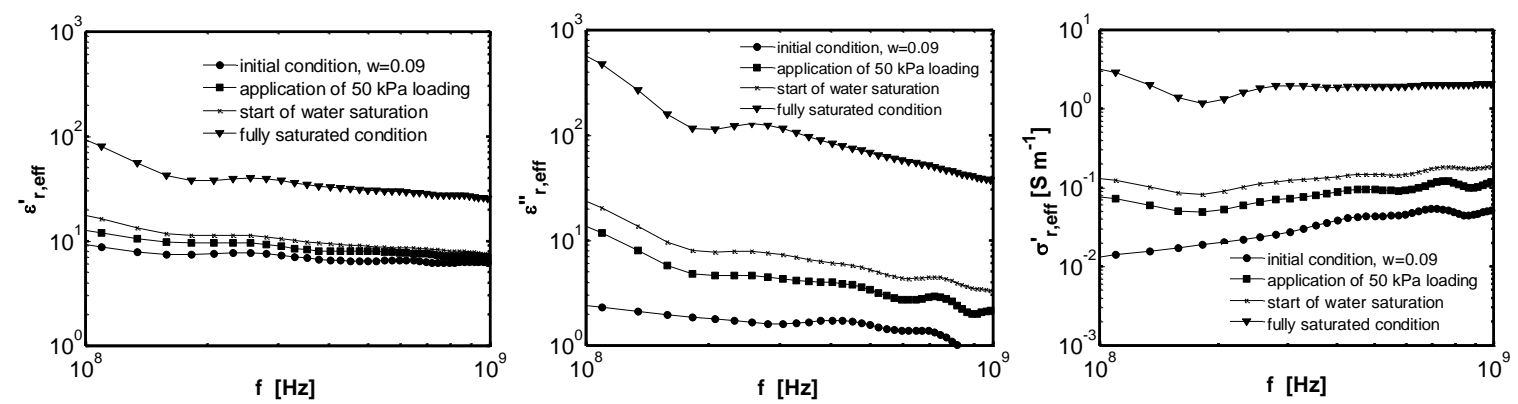

Fig. 5: Plot of time with $\varepsilon_{r, \text { eff }}$ and deformation (top-left), micro-structure of a hydro-collapsible soil before and after collapse triggered by inundation (top-right) and $\varepsilon_{r, \text { eff }}^{*} \sigma_{\text {eff }}^{\prime}=\omega \varepsilon_{0} \varepsilon_{r, \text { eff }}^{\prime \prime}$ as functions of frequency $f$ (bottom) of a collapse test at a stress level of $50 \mathrm{kPa}$.

It can be seen that the measured $\varepsilon^{*}$,eff of the collapsible soil increases rapidly when water is introduced to the specimen in the test box. Casagrande [1] has demonstrated that a portion of the fine-grained fraction of the soil exists as bonding material for the larger-grained particles and that these bonds undergo local compression in the small gaps between adjacent grains resulting in the development of strength, Figure 5 (top-right). When the loaded soil is exposed to moisture, and a certain critical moisture content is reached, the fine silt or clay bridges that are providing the cementation will soften, weaken and/or dissolve to some extent. Eventually, the binders reach a stage where they no longer resist deformation forces and the structure collapses [32]. As the water molecules react and dissolve the clay and/or silt bridges, the concentration of $\mathrm{Na}^{+}, \mathrm{Ca}^{++}, \mathrm{OH}^{-}$and other alkali ions in the pore water solution increases rapidly, producing a rapid increase in the recorded values of complex dielectric permittivity. The rate of increase of the measured $\varepsilon_{r, \text { eff }}$ is higher at the beginning of the start of inundation, but then gradually slows down during the latter stages of the test. This is attributed to the fact that, the rate at which the water molecules react with the fine cementing particles is very high at the initial stage of inundation, but then gradually slows down to a minimum within a time frame of around 1 to 2 hours. In particular, the increase in the measured values of $\varepsilon^{\prime \prime} r$,eff during sample collapse is much higher as compared to that of the $\varepsilon_{r, \text { eff, }}^{\prime}$, Figure 5 (top-left), due to the rapid increase in the amount of dissolved solutes in the pore water solution during the water-driven collapse process which in turn increases the Ohmic and polarization losses in the soil.

\section{Conclusion}

In this study, a new approach for the monitoring of water-driven collapse process in stressed collapsible soils based on experimental high frequency electromagnetic (HF-EM) investigations, conducted by fitting an open ended coaxial line horizontally in to a one dimensional loading device was presented. The variations of complex dielectric permittivity $\varepsilon^{*}{ }_{r, \text { eff }}$ of collapsible soils with changes in moisture content, porosity, matric suction and applied stress was investigated, as the collapse behavior is highly affected by changes in the soil hydro-mechanical conditions. The work presented in this research provides a platform for the identification and improvement of weak deposits such as collapsible soils by using the widely applicable and easy to use HF-EM techniques, such as time domain reflectometry (TDR).

\section{Acknowledgements}

The authors would like to acknowledge the financial support provided by the German Federal Ministry for Economic Affairs and Energy (BMWi) under Grant number 0325547B and the support of Project Management Jülich.

\section{References}

[1] A. Casagrande, "The structure of clay and its importance in foundation engineering," Journal of Boston Society of Civil Engineers, vol. 19, pp. 168-209, 1932.

[2] D. G. Fredlund and J. K. M. Gan, "The collapse mechanism of a soil subjected to one-dimensional loading and wetting," Chapter 9: In Genesis and Properties of Collapsible Soils, Kluwer Academic Publishers, Boston, NATO ASI Series C: Mathematical and Physical Sciences, vol. 468, pp. 173-205, 1995, http://dx.doi.org/10.1007/978-94011-0097-7_9

[3] D. G. Fredlund and H. Rahardjo, Soil mechanics for unsaturated soils. John Wiley and Sons Inc., New York, USA, 1993. 
[4] B. Lin and A.B. Cerato, "Electromagnetic properties of natural expansive soils under one-dimensional deformation," Springer-Verlag Berlin Heidelberg, 2013.

[5] S. R. Evett, R. C. Schwartz, J. A. Tolk and T. A. Howell, "Soil profile water content determination: spatiotemporal variability of electromagnetic and neutron probe sensors in access tubes," Vadose Zone Journal, vol. 8, no. 4, pp. 926-941, 2009, http://dx.doi.org/10.2136/vzj2008.0146

[6] H. M. Jol, "Ground penetrating radar: Theory and applications," Elsevier, Amsterdam, Netherlands, 2009.

[7] D. A. Robinson, S. B. Jones, J. M. Wraith, D. Or and S. P. Friedman, "A review of advances in dielectric and electrical conductivity measurement in soils using time domain reflectometry," Vadose Zone Journal, vol. 2, no. 4, pp. 444-475, 2003, http://dx.doi.org/10.2136/vzj2003.4440

[8] K. Lauer, N. Wagner and P. Felix-Henningsen, "A new technique for measuring broadband dielectric spectra of undisturbed soil samples," European Journal of Soil Science, vol. 63, no. 2, pp. 224-238, 2012, http://dx.doi.org/10.1111/j.1365-2389.2012.01431.x

[9] N. Wagner, K. Emmerich, F. Bonitz and K. Kupfer, "Experimental investigations on the frequency and temperaturedependent dielectric material properties of soil," IEEE Transactions on Geoscience \& Remote Sensing, vol. 49, no. 7, 2011, 2518-2530, http://dx.doi.org/10.1109/TGRS.2011.2108303.

[10] K. Arulanandan, "Soil structure: In situ properties and behaviour," Department of Civil and Environmental Engineering, University of California, Davis, CA, USA, 2003.

[11] E. T. Selig and S. Mansukhani, "Relationship of soil moisture to the dielectric property," Geotech. Eng. Div, American Society of Civil Engineers Proceedings, vol. 101, no. GT8, pp. 755, 1975.

[12] J. B. Hasted, Aqueous dielectrics. Chapman and Hall, London, England, 1973.

[13] G. C. Topp, J. L. Davis and A. P. Annan, "Electromagnetic determination of soil water content: measurements in coaxial transmission lines," Water Resources Research, vol. 16, no. 3, pp. 574-582, 1980, http://dx.doi.org/10.1029/WR016i003p00574

[14] J. Birchak, C. Gardner, J. Hipp and J. Victor, "High dielectric constant microwave probes for sensing soil moisture," in Proceedings of the IEEE, vol. 62, no. 1, pp. 93-98, 1974.

[15] J. A. Huisman, S. S. Hubbard, J. D. Redman and A. P. Annan, "Measuring soil water content with ground penetrating radar," Vadose Zone Journal, vol. 2, no. 4, pp. 476-491, 2003.

[16] L. D. Landau and E. M. Lifshitz, Elektrodynamik der Kontinua. AkademieVerlag, Berlin, Germany, 1993.

[17] J. E. Campbell, "Dielectric properties and influence of conductivity in soils at one to fifty megahertz," Soil Science Society of America Journal, vol. 54, no. 2, pp. 332-341, 1990.

[18] U. Kaatze, "Hydrogen network fluctuations and the microwave dielectric properties of liquid water," Subsurface Sensing Technologies and Applications, vol. 1, no. 4, pp. 377-391, 2000.

[19] W. Ellison, "Freshwater and seawater," in thermal microwave radiation: Applications for remote sensing, (Mätzler C (ed.)), The Institution of Engineering and Technology, London, UK, pp. 431-455, 2006.

[20] M. C. Dobson, F. T. Ulaby, M. T. Hallikainen and M. A. El-Rayes, "Microwave dielectric behavior of wet soil - Part II: Dielectric mixing models," IEEE Transactions on Geoscience and Remote Sensing, vol. GE-23, no. 1, pp. 35-46, 1985.

[21] ASTM, Annual book of ASTM standards. Volume 04.08 Soil and Rock (I): D420-D5876 and Volume 4.09 Soil and Rock (II): D5877-latest, West Conshohocken, PA, USA, 2011.

[22] ASTM D 5298- 94, Standard test method for measurement of soil potential (suction) using filter paper. Designation D 5298-94, American Society for Testing Materials, West Conshohocken, PA, USA, 1994.

[23] Z. M. Mansour, Z. Chik and M. R. Taha, "On the procedures of soil collapse potential evaluation," Journal of Applied Sciences, vol. 8, no. 23, pp. 4434-4439, 2008.

[24] N. Wagner, T. Sokoll and O. Schimmer, "Robust low cost open-ended coaxial probe for dielectric spectroscopy in laboratory and in-situ applications," in: Proceedings of 6th CMM Conference Innovative Feuchtemessung in Forschung und Praxis, Karlsruhe, Germany, 2011.

[25] N. Wagner, M. Schwing and A. Scheuermann, "Numerical 3D FEM and experimental analysis of the open-ended coaxial line technique for microwave dielectric spectroscopy on soil," IEEE Transaction on Geoscience and Remote Sensing, vol. 52, no. 2, pp. 880-893, 2014, http://dx.doi.org/10.1109/TGRS.2013.2245138 
[26] J. M. Blonquist, S. B. Jr. Jones, I. Lebron and D. A. Robinson, "Microstructural and phase configurational effects determining water content: Dielectric relationships of aggregated porous media," Water Resources Research, vol. 42, no. 5, W05424, 2006.

[27] N. Wagner and A. Scheuermann, "On the relationship between matric potential and dielectric properties of organic free soils: a sensitivity study," Canadian Geotechnical Journal, vol. 46, no. 10, pp. 1202-1215, 2009.

[28] D. Robinson, M. Schaap, D. Or and S. Jones, "On the effective measurement of frequency of time domain reflectometry in dispersive and nonconductive dielectric materials," Water Resources Research, vol. 41, no. 2, pp. 19, 2005.

[29] T. J. Kelleners, D. A. Robinson, P. J. Shouse, J. E. Ayars and T. H. Skaggs, "Frequency dependence of the complex permittivity and its impact on dielectric sensor calibration in soils," Soil Sci. Soc. Amer. J., vol. 69, no. 1, pp. 67-76, 2005.

[30] M. A. Hilhorst, "A pore water conductivity sensor," Soil Science Society of America Journal, vol. 64, no. 6, pp. 1922-1925, 2000.

[31] R. P. Ewing and A. G. Hunt, "Dependence of the electrical conductivity on saturation in real porous media," Soil Science Society of America Journal, vol. 5, no. 2, pp. 731-741, 2006.

[32] A. Al-Rawas, "State-of-the-art review of collapsible soils," Science and Technology, Sp. Review, pp. 115-135, 2000. 